\title{
FORENSIC CASES IN THE NORTH OF CHILE: DETERMINATION OF ANTIDEPRESSANT DRUGS IN HUMAN WHOLE BLOOD
}

\author{
FELIPE BRAVO ${ }^{1,2,3}$, CARMEN ZAMBRA ${ }^{1}$, KARINA VENEGAS ${ }^{2}$, \\ DAVID RIOS ${ }^{1,3}$, PEDRO BUC CALDERON ${ }^{1,3,4}$ and JULIO BENITES ${ }^{1,3 *}$ \\ ${ }^{1}$ Facultad de Ciencias de la Salud, Universidad Arturo Prat, Casilla 121, Iquique, Chile. \\ ${ }^{2}$ Laboratorio Referencial Norte. Servicio Médico Legal. Iquique, Chile. \\ ${ }^{3}$ Instituto de EtnoFarmacología (IDE), Universidad Arturo Prat. Iquique. Chile. Avenida Arturo Prat 2120. Casilla 121, Iquique, Chile. \\ ${ }^{4}$ Toxicology and Cancer Biology Research Group, Louvain Drug Research Institute (LDRI), Université Catholique de Louvain, Brussels, Belgium
} (Received: October 5, 2012 - Accepted: December 13, 2012)

\begin{abstract}
The consumption of antidepressant drugs has increased in these last years, leading to severe and lethal poisonings. In this work, analytical tools, namely $\mathrm{GC} / \mathrm{MSD}$ and $\mathrm{GC} / \mathrm{NPD} / \mu \mathrm{ECD}$, were used to identify and quantify several antidepressant drugs including amitriptyline, imipramine, sertraline, fluoxetine, and citalopram in forensic cases in the North of Chile during 2008-2011. Drugs were analyzed in biological arrays like blood. A solid phase extraction by Bond Elut Certify columns was applied in all these processes. Fluoxetine and sertraline were derivatized with pentafluoropropionic anhydride. Prazepam was used as internal standard (IS). The limit of detection (LOD) in blood were $0.5-20.07 \mathrm{ng} / \mathrm{mL}$. The average extraction rate was $89.39 \%$ in blood. The relative standard deviation (RSD) was less than $3.6 \%$, while the intra-day accuracy was $<5.5 \%$ and the inter-day was $<2.4 \%$, referred to RSD. The procedures we have developed allow the quantification of drugs even at low therapeutic doses, a very important issue taking into account the nature of the analyzed arrays.
\end{abstract}

Keywords: antidepressants, gas chromatography, mass selective detector, $\mu$-electron capture detector, solid-phase extraction

\section{INTRODUCTION}

Depression is considered a pathology affecting directly the Central Nervous System leading to behavior troubles with a prevalence of 3 to $5 \%$ of world population. ${ }^{1} \mathrm{~A}$ wide variety of drugs affecting behavior have been developed, and have been regrouped by either structural or pharmacodynamic similarities: Tricyclic antidepressants (TCAs), selective serotonin recapture inhibitors (SSRIs), mono amine oxidase inhibitors (MAOI) and atypical antidepressant drugs. ${ }^{2}$ While these drugs have been successfully utilized, some intoxication fatal cases have been reported, specifically with TCAs family due to their low therapeutic index. ${ }^{3}$ In many clinical trials demonstrating their efficacy, antidepressants were associated with increased rates of suicidality. ${ }^{4}$ Indeed, antidepressants may rapidly energize an anergic patient before reversing their depressed mood. Thus, a potentially suicidal patient may remain depressed but be provided with enough energy to act on preexisting suicidal ideations. ${ }^{5}$

In Chile, an increase of $470 \%$ of antidepressant drugs consumption was determined in a period from 1999 and $2004,{ }^{6}$ a fact that enhances the risk of drug poisoning. Indeed, data from national toxicological agencies showed that $26.18 \%$ of report cases were due to antidepressant drugs. ${ }^{7}$ In this context, forensic toxicology requires not only new systems to separate compounds from complex arrays like blood but also validated methods. Among systems allowing compound separation, the solid phase extraction procedure ${ }^{8,9}$ may be applied for different drugs elution system thus reaching recovery up to $100 \% .{ }^{9}$ Several analytical methods for the detection of antidepressant drugs by using HPLC and GC with different types of detectors such as MSD, UV and others, have been reported..$^{7-12}$

The aim of this study was to report, for the first time, the determination of antidepressant drugs in forensic cases in North of Chile. Finally, two chromatographic methods for detection and quantification of antidepressant drugs in biological arrays like blood were developed and further validated. The selected drugs were grouped on the basis of their physicochemical properties. Fluoxetine (FLX) and sertraline (SRT) were analyzed by GC/NPD/ $\mu$ ECD to determine the presence of halogens and amino groups in their structures. On the other hand, amitriptyline (AMI), imipramine (IMI) and citalopram (CPM) were analyzed by GC/MSD to determine the presence of specific ions.

\section{MATERIALS AND METHODS}

\section{Chemicals and reagents}

Amitriptyline, imipramine, sertraline, fluoxetine, and citalopram were purchased from Cerilliant (TX, USA). PFPA (99\%) and Methanol (HPLC grade $99.9 \%$ ) were from Sigma Aldrich (USA). Ethyl acetate (HPLC grade) was purchased from Fluka (Germany). Dichloromethane (HPLC grade 99.9\%) were purchased from Merck (Germany). Acetonitrile (HPLC grade 99.9\%) was from J.T. Baker (Mexico). Ammonia solutions 25\% (Merck). All other chemicals were ACS reagent grade.

\section{Sample preparation}

The 5 drugs were classified into two groups: group $\mathbf{I}$ : amitriptyline, imipramine and citalopram; and group II: fluoxetine and sertraline, which were analyzed by GC/MSD and GC/NPD/ $\mu \mathrm{ECD}$ respectively.

Samples of whole blood from persons without story of drug consumption and not receiving a pharmacological treatment were obtained from the blood bank of "Dr. Ernesto Torres Galdames" Iquique Hospital and stored at $4{ }^{\circ} \mathrm{C}$ until analysis. Human whole blood was shaken for $1 \mathrm{~min}$ and then homogenized thoroughly. To the homogenate it was added $80 \mu \mathrm{L}$ of a $5 \mathrm{ng} / \mu \mathrm{L}$ solution of prazepam (I.S), and vortexed for 30 seconds. Two $\mathrm{mL}$ of $100 \mathrm{mM}$ pH 6.0 phosphate buffer was added to the group I while to the group II it was added $4 \mathrm{~mL}$ of bidistilled water and $2 \mathrm{~mL}$ of $100 \mathrm{mM} \mathrm{pH} 6.0$ phosphate buffer. The sample solutions were vortexed for $1 \mathrm{~min}$, sonicated at room temperature for 1 hour and centrifuged at 4,000 rpm for $15 \mathrm{~min}$. The clean supernatants corresponding to samples of group I and II were placed in the extraction column.

\section{Solid-phase extraction (SPE)}

The solid-phase extraction was performed using a Bond Elut Certify column. The solid-phase extraction cartridges were preconditioned with $3 \mathrm{~mL}$ of methanol, $3 \mathrm{~mL}$ of water and $1 \mathrm{~mL}$ of $100 \mathrm{mM} \mathrm{pH} 6.0$ phosphate buffer, all under vacuum (no more than $3 \mathrm{~mm} \mathrm{Hg}$ ). The prepared samples (group I and II) were then applied and allowed to pass through the column at a rate of $1 \mathrm{~mL} / \mathrm{min}$. The sorbent was washed with $3 \mathrm{~mL}$ of water and $3 \mathrm{~mL}$ of methanol and further washed with $3 \mathrm{~mL}$ of acetic acid $1 \mathrm{M} \mathrm{pH} 4.0$ and $3 \mathrm{~mL}$ of acetic acid $0.1 \mathrm{M} \mathrm{pH} 4.0$ in the case of group I and II, respectively. To dry the column completely the vacuum was maintained at $10 \mathrm{~mm} \mathrm{Hg}$ for $5 \mathrm{~min}$. Finally, the antidepressant drugs were eluted with $3 \mathrm{~mL}$ of dichloromethaneisopropanol-ammonia $(78: 20: 2 \mathrm{v} / \mathrm{v} / \mathrm{v})$ into amber collection tubes. The solvent was evaporated under a gentle stream of nitrogen and the residue of group I was reconstituted with $100 \mu \mathrm{L}$ of acetonitrile. Drugs in the group II were derivatized with $100 \mu \mathrm{L}$ of pentafluoropropionic anhydride at $50{ }^{\circ} \mathrm{C}$ for $20 \mathrm{~min}$. The solvent was evaporated under a gentle stream of nitrogen and the residue was reconstituted with $100 \mu \mathrm{L}$ of ethyl acetate.

\section{GC-MS}

Chromatographic analysis was carried out on an Agilent Series $6890 \mathrm{~N}$ system (Agilent, USA) equipped with an Automatic Sampler 7683 series linked with injector programmed temperature volatilization (PTV) and DB-5MS capillary columns $(50 \mathrm{~m} \times 0.22 \mathrm{~mm}, 0.33 \mu \mathrm{m}$ film thickness). The injection volume was $5 \mu \mathrm{L}$ in solvent vent mode. Selective mass detector together with a Chemstation software suite (Agilent, USA) version A.09 was used for data processing and instrument control. The temperature of the PTV injector in 
solvent vent mode was set at $70{ }^{\circ} \mathrm{C}$ and the flow rate was kept at $2 \mathrm{~mL} / \mathrm{min}$ using electronic helium as carrier gas. The oven temperature was programmed as follows: the initial temperature was set at $50{ }^{\circ} \mathrm{C}$, held for $3 \mathrm{~min}$, and ramped at $60^{\circ} \mathrm{C} / \mathrm{min}$ to $180^{\circ} \mathrm{C}$, where it was held for $1 \mathrm{~min}$ and again ramped at $40^{\circ} \mathrm{C} /$ min to $230{ }^{\circ} \mathrm{C}$ and held for $2 \mathrm{~min}$, and again ramped at $30{ }^{\circ} \mathrm{C} / \mathrm{min}$ to $315^{\circ} \mathrm{C}$ and held for $4.75 \mathrm{~min}$.

The GC-MS analysis for identification of antidepressant drugs was carried out in gas chromatography equipped with an Agilent 5975 mass selective detector operated in electron impact mode (Agilent USA). The temperatures of the quadrupole, ion source, and mass selective detector interface were 150 , 230 and $300^{\circ} \mathrm{C}$, respectively.

\section{GC-NPD $/ \mu$ ECD}

Chromatographic analysis was carried out on an Agilent Series 6890N system (Agilent, USA) equipped with an Automatic Sampler 7683 series linked with injector programmed temperature volatilization and two DB-5MS capillary columns $(50 \mathrm{~m} \times 0.2 \mathrm{~mm}, 0.33 \mu \mathrm{m}$ film thickness). The injection volume was $5 \mu \mathrm{L}$ in solvent vent mode. A nitrogen-phosphorus detector and a micro-electron capture detector, together with a Chemstation software suite (Agilent, USA) version A.09 were used for data processing and instrument control. The temperature of the PTV injector in solvent vent mode was set at $70{ }^{\circ} \mathrm{C}$ and the flow rate was kept at $1.8 \mathrm{~mL} / \mathrm{min}$ using UHP helium as the carrier gas. The oven temperature was programmed as follows: the initial temperature was set at $50{ }^{\circ} \mathrm{C}$, held for $2 \mathrm{~min}$, and ramped at $60{ }^{\circ} \mathrm{C} / \mathrm{min}$ to $180{ }^{\circ} \mathrm{C}$, where it was held for $1 \mathrm{~min}$ and again ramped at $30^{\circ} \mathrm{C} / \mathrm{min}$ to $250^{\circ} \mathrm{C}$ and held for $1 \mathrm{~min}$, and again ramped at $30^{\circ} \mathrm{C} / \mathrm{min}$ to $315^{\circ} \mathrm{C}$ and held for $6.33 \mathrm{~min}$.

The inlet and GC-NPD and GC- $\mu \mathrm{ECD}$ interface temperatures were kept at $335^{\circ} \mathrm{C}$ and $345^{\circ} \mathrm{C}$, respectively.

\section{RESULTS AND DISCUSSION}

The lack of validated and standardized human testing methods has hindered researchers from characterizing the clinical symptoms and potential public health impact of these drugs of abuse in Chile. Therefore, since a couple of years we are working on the development and validation of chromatographic methods in drug abuse in the North of Chile..$^{13-15}$

To continue and to broad our research interests, this study incorporates solid-phase extraction and internal standard to provide adequate sensitivity and precision for measuring the several antidepressant drugs, including amitriptyline, imipramine, sertraline, fluoxetine, and citalopram, in forensic cases in the I - IV and XV regions of Chile during 2008-2011.

Table 1 shows the linearity, relative standard deviation, limit of detection, limit of quantitation (LOQ), and solid-phase extraction efficiency in human whole blood using GC/MSD and GC/NPD/ $\mu \mathrm{ECD}$ detector. Linearity is the ability of the method to be directly proportional to the concentration of the analytes within a given range. Linearity was assessed using prazepam as an internal standard. Under these conditions, the human whole blood concentrations of amitriptyline, imipramine and citalopram (analyzed by $\mathrm{GC} /$ MSD), were ranged of $5-500 \mathrm{ng} / \mathrm{mL}$. For fluoxetine and sertraline (analyzed by $\mathrm{GC} / \mathrm{NPD} / \mu \mathrm{ECD})$, the concentrations were ranged of $25-1500 \mathrm{ng} / \mathrm{mL}$.

Correlation coefficients were $r^{2}>0.983$ for human whole blood obtained for each antidepressant compounds. The ranges of linearity were satisfactory with respect to the subtherapeutic and toxic range for forensic and clinical purposes.

Table 1. Linearity, relative standard deviation (RSD), limit of detection (LOD), limit of quantitation (LOQ), and solid-phase extraction efficiency in human whole blood, using GC/MSD and GC/NPD/ $\mu \mathrm{ECD}$ detector.

\begin{tabular}{|c|c|c|c|c|c|c|c|}
\hline Drugs & $\begin{array}{c}\text { Tested } \\
\text { Detector } \\
(\mathrm{ng} \mathrm{mL}-1)\end{array}$ & $\left(\mathrm{r}^{2}\right)^{*}$ & $\mathrm{RSD}$ & $\begin{array}{c}\text { LOD } \\
\left(\mathrm{ng} \mathrm{mL} \mathrm{m}^{-1}\right)\end{array}$ & $\begin{array}{c}\text { LOQ } \\
\left(\mathrm{ng} \mathrm{mL}^{-1}\right)\end{array}$ & $\begin{array}{c}\text { Whole blood } \\
\text { SPE } \\
\text { efficiency }(\%)\end{array}$ & Detector \\
\hline Amitriptyline & $20-500$ & 0.997 & 0.131 & 4.39 & 13.31 & 82.70 & MSD \\
\hline Imipramine & $30-500$ & 0.998 & 0.094 & 0.50 & 1.53 & 82.70 & MSD \\
\hline Citalopram & $5-500$ & 0.997 & 0.166 & 0.54 & 1.64 & 101.85 & MSD \\
\hline Prazepam & 400 & $\mathrm{ND}$ & $\mathrm{ND}$ & $\mathrm{ND}$ & $\mathrm{ND}$ & 101.85 & MSD \\
\hline Fluoxetine & $50-1500$ & 0.997 & 0.661 & 20.07 & 60.82 & 85.90 & NPD \\
\hline & & 0.988 & 0.570 & 8.36 & 25.32 & & $\mu \mathrm{ECD}$ \\
\hline Sertraline & $25-600$ & 0.983 & 2.091 & 1.08 & 3.28 & 89.22 & $\mathrm{NPD}$ \\
\hline & & 0.992 & 1.867 & 5.03 & 15.25 & & $\mu \mathrm{ECD}$ \\
\hline Prazepam & 400 & $\mathrm{ND}$ & $\mathrm{ND}$ & $\mathrm{ND}$ & $\mathrm{ND}$ & 86.62 & $\mathrm{NPD}$ \\
\hline & & $\mathrm{ND}$ & $\mathrm{ND}$ & $\mathrm{ND}$ & $\mathrm{ND}$ & & $\mu \mathrm{ECD}$ \\
\hline
\end{tabular}

${ }^{*} \mathrm{r}^{2}=$ Square of correlation coefficient with a weighting factor of $1 /$ concentration.

$\mathrm{ND}=$ Not determined

The LODs were calculated based on the standard deviation of the response and the slope (S) of the calibration curve(s) at levels approximating the LOD according to the formula: $\mathrm{LOD}=3.3(\mathrm{SD} / \mathrm{S})$. In whole blood, the $\mathrm{LOD}$ for amitriptyline, imipramine and citalopram varied between 0.50 and $4.39 \mathrm{ng} /$ $\mathrm{mL}$. For fluoxetine and sertraline varied from 1.08 to $20.07 \mathrm{ng} / \mathrm{mL}$. The LOD values clearly indicated that this method is quite sensitive for antidepressant drugs analysis in human whole blood samples.

The LOQ is the lowest concentration that can be measured on the standard curves with acceptable reproducibility. The LOQ values for amytriptiline, imipramine and citalopram varied between 1.53 and $13.31 \mathrm{ng} / \mathrm{mL}$ and 3.25 and $60.82 \mathrm{ng} / \mathrm{mL}$ for fluoxetine and sertraline. The LOQ determined for the tested analytes allowed the measurement of subtherapeutic and abuse/toxic concentrations of these compounds. Therefore, this method may be used in routine screening and quantitation of antidepressant drugs in autopsy and clinical samples.

The solid phase extraction was carried out in triplicate at three concentrations (low, medium and high) of each compound in human whole blood. As shown in Table 1, the solid-phase extraction efficiency was more than $82 \%$, for antidepressant drugs.

Table 2 shows the results obtained for intra-assay and inter-assay precision calculations and selected ions used for qualification and quantification of all the analytes. Inter-day and intra-day precision were $<2.3 \%$ and $<5.5$ for all analytes respectively. Precision of analytes under investigation at reported concentrations reach the internationally established acceptance criteria. ${ }^{16-19}$

Representative chromatogram of the amitriptyline, imipramine and citalopram drugs analyzed by GC/MS; fluoxetine and sertraline by GC/NPD/ $\mu E C D$ are shown in Fig. 2. Prazepam was used as internal standard. The formation of molecular peaks of prazepam and antidepressants (group I) at $\mathrm{m} / \mathrm{z} 269$ and 58 respectively is well-demonstrated in the ion chromatograms (Fig. 2).

Adverse effects due to tricyclic antidepressant overdose have being produced for many years, and at present time the most common tricyclic taken 
in fatal overdose are dothiepin and amitriptyline. ${ }^{20}$ Table 3 shows amitriptyline concentrations in human whole blood samples in acute intoxication cases detected in the North of Chile during 2008 - 2011. Gender difference was observed in death incidence by amitriptyline drugs, indeed the eight reported cases $(100 \%)$ were female. It should be noted that in Europe, antidepressants were used in $19 \%$ of women but only $4.8 \%$ of men. ${ }^{21}$ The amitriptyline concentrations, obtained from real autopsy samples, were determined by the GC/MSD method, and drug concentrations ranged between $450 \mathrm{ng} / \mathrm{mL}-5200$ $\mathrm{ng} / \mathrm{mL}$. The international literature reports that antidepressants concentrations over than $1000 \mathrm{ng} / \mathrm{mL}$ are likely to be fatal. ${ }^{20}$ It should be noted that all cases, amitriptyline concentrations largely exceeded toxic doses. Table 3 shows 3 cases correspond to ingested tricyclic antidepressant drug as amitriptyline. On the other hand, it may be argued that remaining cases had ingested a drug "cocktail," including one or more antidepressant substances and other drugs as cocaine and benzodiazepines. Indeed, as reported by Kerr et al. ${ }^{20}$ the main pharmacological properties of tricyclics, namely inhibition of norepinephrine reuptake at nerve terminals, direct $\alpha$ adrenergic block, a membrane stabilizing or quinidine-like effect on the myocardium and anticholinergic action, may cause the toxic effects of tricyclic antidepressants.<smiles>CN(C)CCC=C1c2ccccc2CCc2ccccc21</smiles>

Amitriptyline

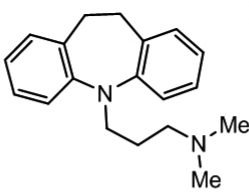

Imipramine

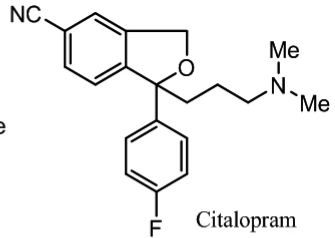

Citalopram<smiles>CNCCC(Oc1ccc(C(F)(F)F)cc1)c1ccccc1</smiles>

Fluoxetine<smiles>CNC1CCC(c2ccc(Cl)c(Cl)c2)c2ccccc21</smiles>

Sertraline
Figure 1. Structures of antidepressant drugs studied: amitriptyline, imipramine, citalopram, fluoxetine, and sertraline.

Table 2. Intra- and inter-day precision, for antidepressant drugs.

\begin{tabular}{|c|c|c|c|}
\hline \multirow{2}{*}{ Drugs } & $\begin{array}{c}\text { Inter-day } \\
\text { precision* }\end{array}$ & $\begin{array}{c}\text { Intra-day } \\
\text { precision** }\end{array}$ & \multirow{2}{*}{ Detector } \\
\cline { 2 - 3 } & RSD (\%) & RSD (\%) & \\
\hline Amitriptyline & 1.252 & 4.816 & MSD \\
\hline Imipramine & 2.026 & 5.470 & MSD \\
\hline Citalopram & 2.105 & 5.334 & MSD \\
\hline Fluoxetine & 1.164 & 2.287 & NPD \\
\hline & 1.459 & 1.636 & $\mu \mathrm{ECD}$ \\
\hline Sertraline & 2.356 & 1.056 & $\mathrm{NPD}$ \\
\hline & 1.599 & 0.780 & $\mu \mathrm{ECD}$ \\
\hline
\end{tabular}

$$
*_{\mathrm{n}}=5
$$

$* * \mathrm{n}=15$ ( 5 repetitions for 3 days)

In summary, antidepressants can increase the risk of suicidal thoughts and behavior in patients under particular conditions. Consequently, the use of an antidepressant medication and the risk of suicidality has become an issue of concern.

\section{CONCLUSION}

The present study shows the validation of GC/MSD and GC/NPD/ $\mu$ ECD methods for the analysis of antidepressant drugs in whole blood samples. The main advantages of this method are its selectivity and sensitivity for clinical and postmortem toxicological analysis. The current method is being applied by the Laboratorio Referencial Norte of the Servicio Medico Legal, Iquique, in forensic cases in the North of Chile.

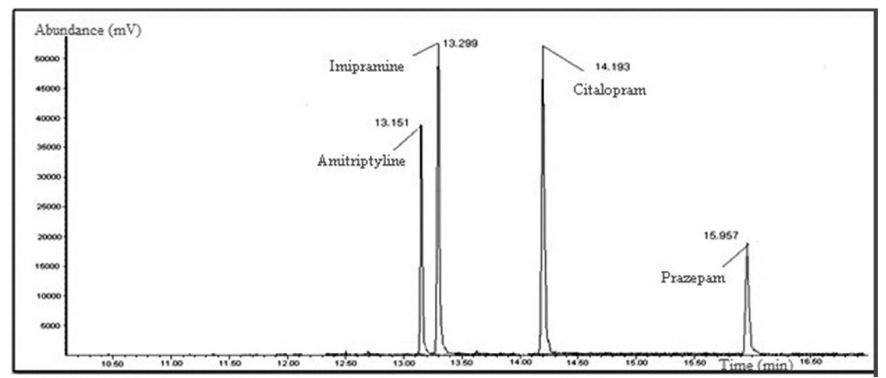

a) Chromatogram of the amitriptyline, imipramine and citalopram analyzed by GC/MSD

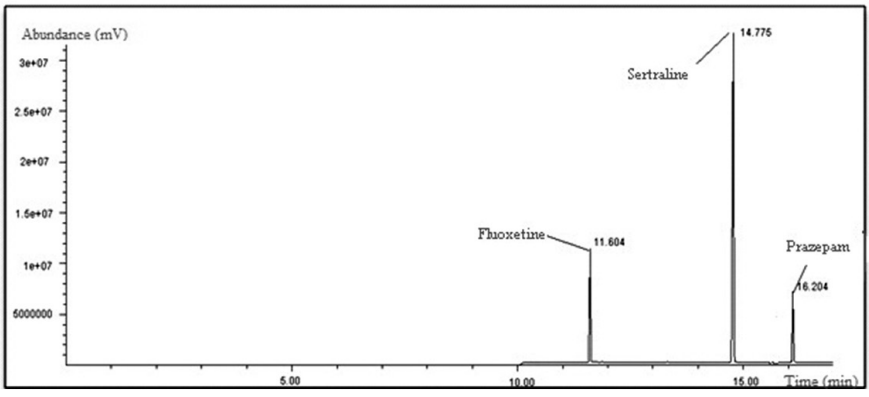

b) Chromatogram of the fluoxetine and sertraline analyzed by GC/NPD

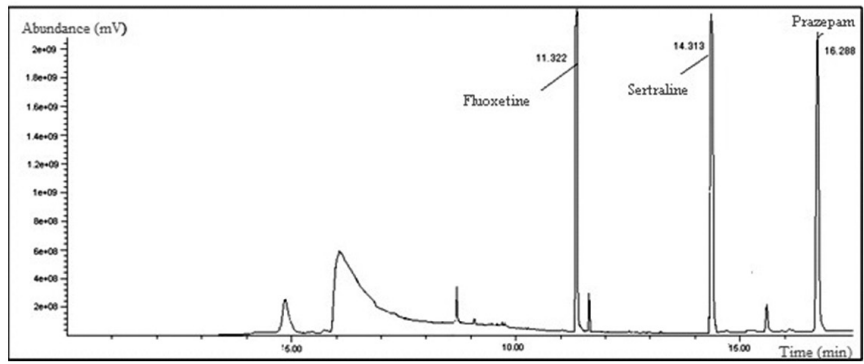

c) Chromatogram of the fluoxetine and sertraline analyzed by $\mathrm{GC} / \mu \mathrm{ECD}$

Figure 2. Chromatograms of the antidepressant drugs analyzed by GC/MS and $\mathrm{GC} / \mathrm{NPD} / \mu \mathrm{ECD}$

\section{ACKNOWLEDGEMENTS}

We thank Laboratorio Referencial Norte, Servicio Medico Legal, Iquique and Universidad Arturo Prat for financial support of this study. 
Table 3. Acute amitriptyline intoxication detected in human whole blood in the North of Chile during $2008-2011$.

\begin{tabular}{|c|c|c|c|c|}
\hline Gender & Concentration $\mathrm{ng} / \mathrm{mL}$ & Other drugs detected & Year & Region \\
\hline Female & 1850 & - & 2008 & II (Antofagasta) \\
\hline Female & 3000 & - & 2008 & XV (Arica) \\
\hline Female & 5200 & Alprazolam $(20 \mathrm{ng} / \mathrm{mL})$ & 2008 & I (Iquique) \\
\hline Female & 2230 & Sertraline $(90 \mathrm{ng} / \mathrm{mL})$ & 2009 & IV (La Serena) \\
\hline Female & 2200 & Midazolam $(30 \mathrm{ng} / \mathrm{mL})$ & 2009 & II (Calama) \\
\hline Female & 3100 & Metoclopramide * & 2010 & II (Antofagasta) \\
\hline Female & 450 & Cocaine $(40 \mathrm{ng} / \mathrm{mL})$ & 2010 & II (Calama) \\
\hline Female & 1000 & - & 2011 & II (Calama) \\
\hline
\end{tabular}

$(*)=$ Levels not determined

\section{REFERENCES}

1. A.H. Dawson, Cyclic antidepressant drugs, in: R.C. Dart (Ed.), Medical Toxicology, third ed., Lippincott Williams \& Wilkins, Philadelphia, 2004, pp. 834-843.

2. A. Lajeunesse, C. Gagnon, and S. Sauvé. Analytical Chemistry 80, 53255333, (2008).

3. J. Veris-van Dieren, L. Valk, I. van Geijlswijk, D. Tjan, A. van Zanten. The Journal of Medicine 65, 142-146, (2007).

4. M. H. Teicher, C. A. Glod, J. O. Cole. Drug Safety 8, 186-212, (1993).

5. T. J. Feuerstein, R. Jackisch. Psychopharmacology 90, 422, (1980).

6. M. Jirón, M. Machado, I. Ruiz, Revista Médica de Chile, 136, 1147-1154, (2008).

7. Casos de intoxicaciones humanas por categoría de agente y edad. Centro de Información Toxicológica Red Salud UC. Disponible en: http://www. cituc.cl/files/arc/ci_estadisticas/6857278824b26b0d8d586e.pdf

8. T. Shinozuka, M. Terada, E. Tanaka. Forensic Science International, 162, 108-112. (2006).

9. A. Jasinska, B. Starczewska. Journal of Pharmaceutical and Biomedical Analysis, 31, 795-799, (2003).

10. A. Saber. Talanta, 78, 295-299, (2009).

11. J. Berzas, M. Villaseñor, A. Contento, E. Aguas. Journal of Pharmaceutical and Biomedical Analysis, 38, 52-59, (2005).
12. A. de Castro, M. Ramírez, M. Laloup, N. Samynb, G., De Boeck, M. Wood, V. Maes, Lopez-Rivadulla. Journal of Chromatography A, 1160, 3-12, (2007).

13. F. Bravo, C. Lobos, K. Venegas, J. Benites. Journal of the Chilean Chemical Society, 55 (4), 454-457, (2010).

14. F. Bravo, D. Gonzalez, J. Benites. Journal of the Chilean Chemical Society, 56 (3), 799-803, (2011).

15. F. Bravo, C. Contzen, J. Mollo, P. Buc Calderon, J. Benites. Journal of the Chilean Chemical Society, 57 (3), 1253-1255, (2012).

16. H. Juan, Z. Zhiling, L. Huande, J. Chromatography B 820 (2005) 33.

17. J.J. Berzas, M.J. Villase, A.M. Contento, E. Aguas. Journal of Pharmaceutical and Biomedical Analysis, 38, 52-59, (2005).

18. M. Castro, M. Ramírez, N. Laloup, G. Samynb, M. De Boeck, V. Wood, M. Maes, Lopez-Rivadulla. Journal of Chromatography A, 1160, 3-12, (2007).

19. J. J. Berzas, M. J. Villase, C. Guiberteau, V. Rodríguez. Journal of Chromatography A, 1123, 130-133, (2006).

20. J. M Petit, D.G Spiker, J. F Ruwitch, V. E. Ziegler. Clinical Pharmacology Therapy;21: 47-51, (1977).

21. B. Müller-Oerlinghausen, A. Berghöfer. Journal of Clinical Psychiatry 60, 94-99, (1999). 